From the Thoracic Surgery Unit and the *Division of Pneumology, Inselspital, University of Berne. Switzerland

\title{
Video-assisted Thoracic Surgery: Risks and Benefits
}

\author{
H. B. Ris, D. Lardinois und M. Gugger**
}

Key words: Video-assisted thoracoscopic surgery - pleural diseases - mediastinal pathologies - lung affections.

Schlïsselwörter: Videoassistierte Thorakoskopie - Pleuraerkrankungen - Lungenparenchymerkrankungen - mediastinale Pathologien.

Summary: Background: Thoracoscopy has been used throughout this century, especially in the treatment of pleural disease. The introduction of video-assistance and especially designed instruments such as stapling devices in 1992 led to a worldwide and enthusiastic application for the treatment of a variety of thoracic pathologies.

Methods: This report summarizes our experience gained from 1013 consecutive VATS procedures performed since 1990 for various indications in order to clarify its role for surgery of thoracic pathologies.

Results: 234 patients underwent VATS for pleural biopsy, 154 for talcage, 163 for pulnonary wedge resections in order to clarify interstitial disease or indetermined nodules, 126 for spontaneous pneumothorax, 91 for decortication of empyema. 63 for symphatectomy, 55 for biopsy of mediastinal lesions, 29 for pericardial effusions (fenestration), 25 for lung volume reduction surgery, 17 for excision of mediastinal cysts and 12 for excision of neurogenic tumors of the posterior mediastinum. Conclusions: Our results demonstrate that VATS has gained established acceptance for several indications, however, caution in application of VATS is clearly indicated for some diseases, especially for thoracic malignancies.

(Acta Chir. Austriaca 1999; 31: 286-291)

Möglichkeiten und Grenzen der Videothorakoskopie Zusammenfassung: Grundlagen: Thorakoskopische Interventionen werden seit Beginn dieses Jahrhunderts durchgeführt, insbesondere zur Diagnostik und Therapie pleuraler Erkrankungen. Die Einführung der Videothorakoskopie sowie der endoskopischen Klammernähapparate 1992 hat zu einer enthusiastischen Verbreitung dieser Methode zur Behandlung einer Vielzahl von thorakalen Pathologien geführt.

Methodik: In dieser Studie wird unsere Erfahrung anhand von seit 1990 an unserer Institution durchgeführten, 1013 konsekutiven Thorakoskopien hinsichtlich Indikation und Resultate dargestellt, um die Rolle der Videothoraskoskopie für verschiedenste thorakale Pathologien klarer zu definieren.

Ergebnisse: 234 Patienten wurden mittels videoassistierter Thorakoskopie pleurabiopsiert, in 154 Patienten erfolgte eine Talkpleurodese, in 163 eine Lungenkeilresektion im Hinblick auf eine offene Lungenbiopsie oder zur histologischen Aufarbeitung eines peripheren Rundherdes, in 126 die thorakoskopische Behandlung eines Spontanpneumothorax, in 91 die Dekortikation eines pleviraien Empyems, in 63 eine thorakale Sympathektomie, in 55 eine Lungenvolumenreduktionstherapie, in 29 Patienten eine Perikardfenestration, in 17 die Exzision von mediastinalen Zysten und in 12 eine Exzision von neurogenen Tumoren des posterioren Mediastinums.

Schlußfolgerungen: Unsere Resultate zeigen, daß die videoassistierte Thorakoskopie mittlerweile ein klar akzeptiertes Verfah-

Corresponding address: H. B. Ris, M. D., Service de Chirurgie, CHUV, Centre Hospitalier Université Vaudois, Lausanne, Switzerland.

Fax: $++41 / 21 / 3142358$

E-mail: Hans-Beat.Ris@chuv.hospvd.ch ren hinsichtlich verschiedener Indikationen darstellt, während bei anderen Indikationsstellungen, insbesondere bei Malignomen im Thoraxbereich. die Rolle der Thorakoskopie noch ungenügend geklärt ist.

\section{Introduction}

Thoracoscopy has been used throughout this century, especially in the treatment of pleural diseases. The introduction of videoassistance and especially designed instruments such as stapling devices in 1992 led to a worldwide and enthusiastic application for the treatment of a variety of thoracic pathologies. Since video-assisted thoracoscopic surgery (VATS) is believed to result in less postoperative pain and morbidity than conventional accesses, it has quickly become very popular for patients and referring physicians, leading to a somewhat uncritical application in the field of thoracic surgery. There is no doubt that VATS has meanwhile gained established acceptance for several indications, however. caution in the application of VATS is clearly indicated for some diseases, especially for thoracic malignancies. One should remember that VATS does not really mean "minimally invasive surgery" but in fact "minimal access surgery", indicating that the procedure within the chest cavity - performed by VATS or by a conventional access - should follow the same well-established principles. This report summarizes or experience gained from 1.013 consecutive VATS procedures performed since 1990) for various indications (Tab. 1). However, since this is a single-institution experience, our reflections may not necessarily correspond to those from other groups, especially regarding anatomical lung resections and mediastinal surgery.

\section{Pleural diseases}

Pleural biopsy: Histological assessment of pleural diseases is a well-established indication for VATS in order to clarify pleural affections of unknown origin (3). It is not only helpful to establish or exclude malignancy but also to confirm or exclude benign diseases such as tuberculosis which is again increasingly observed. Mesothelioma is also increasingly recognized in recent years and multiple specimens of different sites are usually required to confirm the diagnosis in an early stage of disease. Since mesothelioma tend to grow through the incision sites. postoperative irradiation of the trocar sites is recommended (2).

Tablel. Indications of 1.013 consecutive patients requiring videoassisted thoracoscopic interventions.

\begin{tabular}{|l|c|}
\hline Pleural biopsy & 234 \\
\hline Talc pleurodesis & 154 \\
\hline Wedge resections (incerstitial disease, nodules) & 163 \\
\hline Treatment of pneumothorax & 126 \\
\hline Decortication for empyema & 91 \\
\hline Symphatectomy & 63 \\
\hline Biopsy of mediastinal lesions & 55 \\
\hline Pericardial window & 29 \\
\hline Lung volume reduction surgery & 25 \\
\hline Excision of mediastinal cysts & 17 \\
\hline Excision of neurogenic tumors & 12 \\
\hline Thoracic duct ligation (chylothorax) & 3 \\
\hline
\end{tabular}



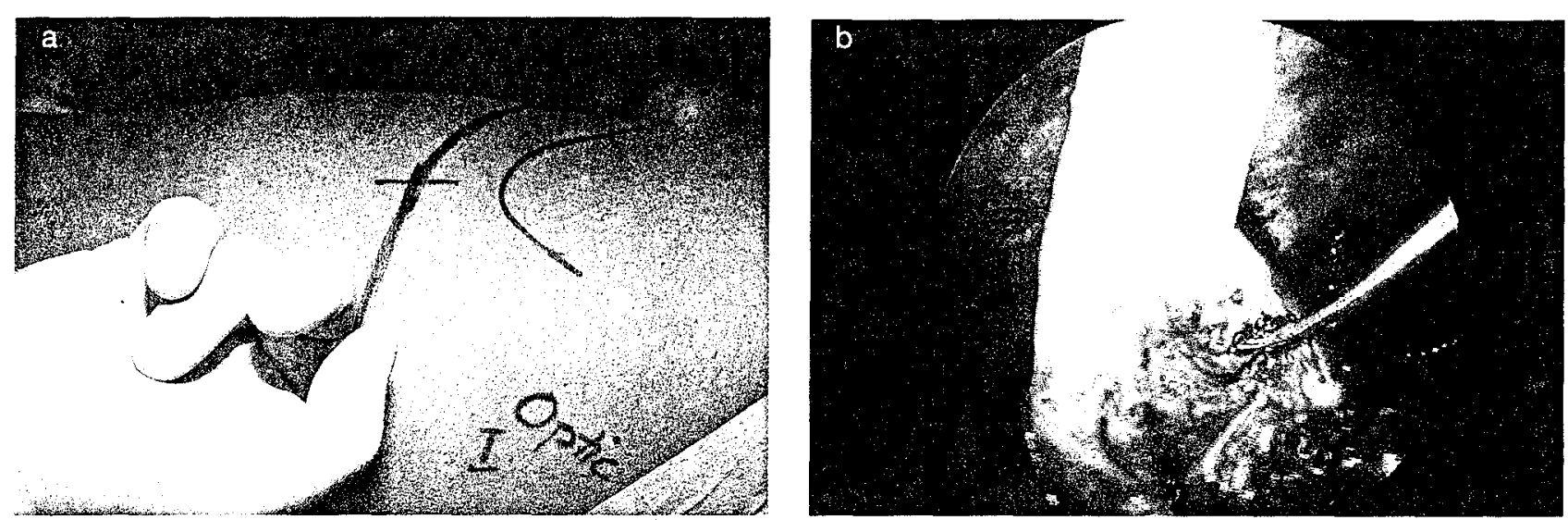

Fig. I. Video-assisted thoracoscopic debridement of stage II emplenta: An incision of $3 \mathrm{~cm}$ is made in the ventrat aspect of a presumed thoracotomy line and the operator's finger is introduced into the chest cavity to assess the chronicity of the empyema (a); fibrin and loculations are evacuated under endoscopic vision and the fibrin peet is dissected from the surface of the lang (b).

Talc pleurodesis: Pleurodesis is performed to promote adhesion formation between the visceral and parietal pleura in patients with pleural effusions. It can be accomplished using different techniques including talc poudrage, chemical pleurodesis, mechanical abrasion, and argon beam coagulation (3). Talc poudrage has shown excellent results provided that the lung is capable to completely expand after evacuation of the effusion. This has to be ensured by thoracocentesis or insertion of a chest tube followed by radiographic control before talcage is performed. No more than $5 \mathrm{~g}$ of talc should be used and talc should only be offered to patients with a restricted life expectancy in order to prevent late sequelae of talc administration. VATS enables a uniform and equally distributed application of talc within the chest cavity under direct vision which does not require double lung intubation. Alternatively. talc slurry may be applied through the chest tubes in those patients who do not tolerate general anesthesia which is efficient and cost effective in the treatment of malignant effusions (28).

Empyema: Pleural empyema is a relevant disease involving a large number of patients, with severe and disabling sequelate for patients with unrecognized or incorrectly treated disease. As defined by the American Thoracic Society in 1962, pleural empyema may pass from its exudative form through a fibrinopurulent phase before becoming organized. As a consequence, the treatment must be chosen accordingly. Since 1992, we have adopted a standardized technique using VATS debridement for stage II empyema (24). Enrollment criterias were systemic signs of infection (fever, weight loss, pain) with loculated pleural effusions consistent with empyema on CT-scan or positive bacterial cultures at thoracocentesis, and a history of less than 3 weeks after onset of fever or pleural effusion. A VATS approach was offered to patients fulfilling the enrollment criteria and consent was obtained from all patients to proceed to decortication via thoracotomy if the empyema was judged to be chronic. After double lumen intubation, a standard posterolateral incision was drawn on the skin of the patient placed in lateral position. An incision of $3 \mathrm{~cm}$ was made in the ventral aspect of this line and the operator's index finger was introduced into the thoracic cavity (Fig. 1 a). This digital exploration was found to be helpful in assessing the chronicity of the empyema; a rigid and narrowed intercostal space as well as a thick and stiff peel between the lung and chest wall were signs of chronicity usually inaccessible to a VATS approach. Adhesions between the lung and the chest wall were broken and the pleural space was circumferentially freed by dissection using the index finger and a suction device. The optic was inserted several centimeters apart from this initial incision and fluid, loculations and septa were removed by suction under endoscopic control. The lung was freed from the chest wall with special attention directed to complete debridement of the costodiaphragmatic sulcus. The instruments were inserted through the initial incision without using trocars. This allowed for quick and efficient removal of debris and fibrin deposits. Visceral decortication was performed by use of a dissector while holding the lung (or the peel) by a duval forceps inserted through an additional port (Fig. I b). If VATS was judged unrewarding during the operation a standard posterolateral thoracotomy was performed (which included the 2 previously performed incisions) followed by decortication. 135 consecutive patients were operated for stage II and III empyema at our institution between 1992 to 1998. In 91 patients a VATS approach was chosen and in 58 patients the procedure could be accomplished while in 33 patients a conversion thoracotomy with decortication was performed. The mortality rate of the whole series was $4.5 \%$, the recurrence rate requiring a 2 nd procedure was 0 after open decortication, and $3.6 \%$ after VATS debridement. The mean duration of chest tube drainage and hospitalization after VATS debridement and open decortication were 4.1 and 6.4 days, and 12.3 and 15.1 days, respectively. Postoperative spirometry 6 months after VATS debridement revealed a mean postoperative VC of $84.8 \pm 14.9 \%$ predicted (range $37 \%$ to $112 \%$ ). In $52 \%$ of the patients VC was $>90 \%$ predicted. The mean FEVI was $88.6 \pm 19.2 \%$ predicted ranging from $36 \%$ to $113 \%$. In $69 \%$ of the patients FEVI was $>90 \%$ predicted. The worst results were obtained in the 2 patients after reoperation for recurrent empyema with a FEVI after the 2 nd operation of $34 \%$ and $45 \%$ predicted, respectively. VATS is a safe and useful tool in the treatment of fibrinopurulent empyema with loculations failing to respond to closed chest tube drainage and antibiotics. However. failure of recognizing the limits of VATS in the treatment of empyema might result in recurrence and poor outcome with respect to pulmonary function. Open decortication should be performed liberally if the degree of chronicity is judged to be too far advanced and this should be done during the same operation if required. Finger palpation with assessment of the narrowing and rigidity of the intercostal space, the thickness of the underlying pleural peel and the degree of adherence of the lung to the chest wall was found especially helpful to determine whether or not VATS debridement may be successfully used, and this often avoided a lengthy and fruitless VATS attempt.

VATS was found to be also very helpful for evacuation of a persistent hemothorax after interventions and chest trauma (19). Clotted blood may be present leading to occlusion of chest tubes and is therefore not amenable to drainage. These clots are easily removed under VATS guidance with prevention of trapped lung and fibrothorax. In contrast, acute and severe hemorrhage into the chest after chest trauma usually requires immediate emergency thoracotomy in order to gain quick hemostasis and prevent exsanguination.

Pericardial window: Chronic or recurrent pericardial etfisions are often related to underlying malignant disease such as 

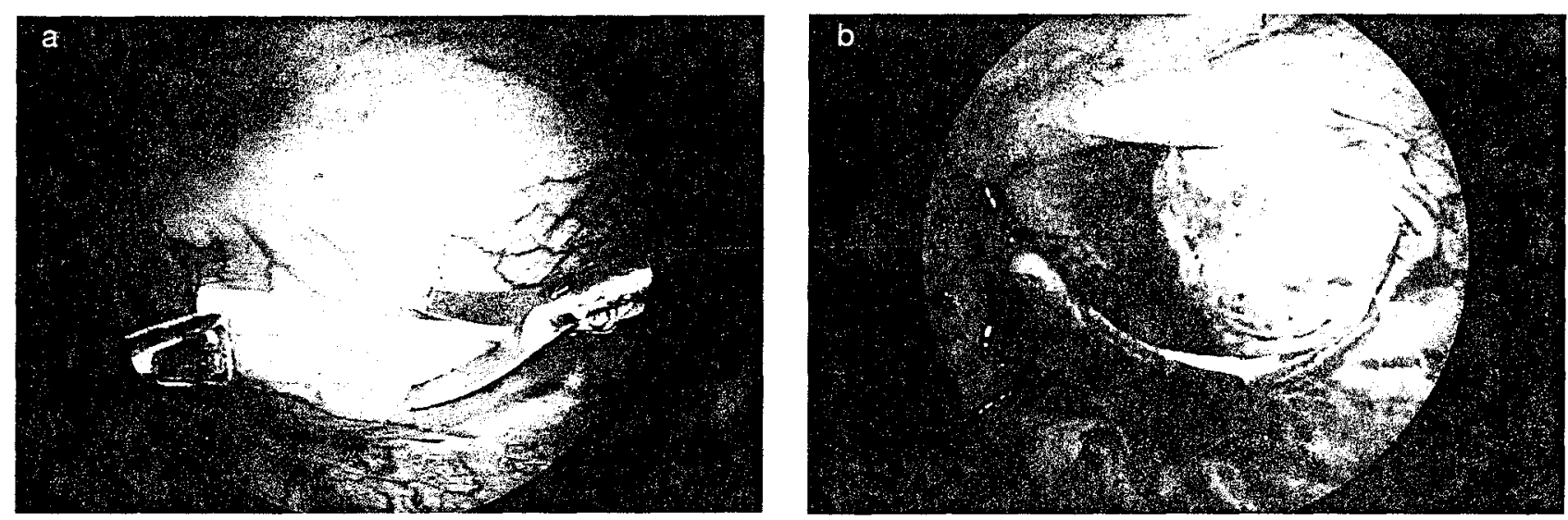

Fig. 2. Video-assisted pericardial fenestration: the pericardium is grasped and incised with scissors (a), and a window of $4 \times 4 \mathrm{~cm}$ is created (b).

lung and breast cancer and malignant lymphoma. However, $50 \%$ of pericardial effusions in patients with known malignancies are benign. Since survival is significantly better in these patients than in those with malignant effusions, diagnosis in these situations is essential. Moreover, pericardial effusions may be related to other diseases such as infections, post-irradiation sequelae, uraemia, collagenoses and myocardial infarction. In a substantial number of patients concurrent pleural pathology is present requiring a simultaneous pleuropericardial diagnosis. Approximately half of the patients suffering from pericardial effusions present with symptoms of cardiac tamponade. In these situations relief of symptoms by means of pericardial decompression is required irrespective of the underlying cause. While percutaneous catheter drainage and balloon pericardiotomy are increasingly performed for diagnostic and therapeutic purposes, recurrent or loculated effusions are best managed surgically with a pericardial window. Video-assisted thoracoscopic pericardial fenestration has demonstrated usefulness in this respect since this technique affords the opportunity to create a pericardial window of sufficient size. Since 1992, pericardial fenestration has been offered by use of VATS at our institution to patients with recurrent or symptomatic pericardial effusions and with effusions of unknown origin (10). Inciusion criteria consisted of echocardiographically documented pericardial effusions requiring further diagnosis or relief of symptoms of tamponade and persistent or recurrent effusions after percutaneous drainage and balloon pricardiotomy. Exclusion criteria consisted of echocardiographic or radiological signs of constrictive pericarditis, and pericardial tamponade due to previous cardiac surgery or blunt and penetrating chest trauma. A CT scan was performed in order to identify additional pleural pathology and to determine the site of intervention. The scope was inserted through the 5 th intercostal space at the anterior axillary line and 2 additional thoracoports were placed in the 6th intercostal space. Any concomitant pleural effusion was evacuated and pleural pathology was biopsied. A pericardiocentesis was performed under direct vision and the fluid collected for cytological and microbiological analysis. The pericardium was grasped with a thoracoscopic Duval forceps and incised with curved thoracoscopic Metzenbaum scissors (Fig. 2 a). Loculations and septa were broken and the heart circumferentially freed with a thoracoscopic Senning suction device. A pericardial window was created with a minimum size of $4 \times 4 \mathrm{~cm}$ while carefully protecting the phrenic nerve (Fig. 2 b). In situations with a combined malignant pericardial and pleural effusion, talc was applied under direct vision on the pleural dome, the chest wall and the diaphragm but not on the mediastinal part of the chest cavity. A chest tube was inserted through one of the thoracoport sites into the chest cavity with no attempt to drain the pericardium. 29 patients underwent thoracoscopic pericardial fenestration since 1992. Histological, cytological and microbiological examinations of the samples revealed inflammation in $33 \%$ of the patients, malignancy in $29 \%$ uraemia in $17 \%$ and post-irradiation sequelae in $13 \%$. Additional talc pleurodesis was performed in $25 \%$ of the partients suffering from a concomitant malignant pleural effusion. There was no treatment related 30 -daly mortality but 2 patients $(8 \%)$ died due to progression of malignancy. Follow-up 3 months after the operation revealed relief of symptoms in all surviving patients but echocardiography showed a recurrent pericardial effusion in one patient suffering from viral infection which was asymptomatic and without hemodynamic significance. No recurrence was observed in patients having undergone talc pleurodesis for concomitant malignant pleural effusion. We found VATS well suited for pericardial fenestration. especially for loculated effusions, recurrent effusions after previously performed percutaneous catheter drainage manoeuvres and effusions with additional pleural disease.

\section{Lung diseases}

Lung biopsy: VATS has become a true alternative to open thoracotomy for the diagnosis of diffuse infiltrative lung disease (17). This maly result in decreased morbidity as compared to conventional procedures for patients requiring pulmonary wedge resections and allows at the same time a more throughout exploration of the entire chest cavity than does a limited thoracotomy. However, single lung ventilation is required for VATSguided wedge resections. Ventilated patients with diffuse lung disease requiring a biopsy are therefore still best accessed by a small anterolateral thoracotomy for this purpose. Wedge resections by use of stapling devices are now preferred over pinch biopsies since histological diagnosis might be difficult to obtain in diffuse interstitial lung diseases, and large samples of representative areas are therefore mandatory. Moreover, prolonged air leaks are less likely after stapling than after "pinch" biopsy techniques.

Indeterminate peripheral pulmonary module: VATS has become the preferred method tor excisional biopsy of indeterminate peripheral pulmonary nodules. The term peripheral pulmonary nodule is used to define spherical lesions surrounded by lung parenchyma measuring less than $3 \mathrm{~cm}$ in diameter (17). A variety of parenchymatous pathologies, both benign and malignant may present as pulmonary nodules and may require histological confirmation. Radiological characteristics of "benignity" are often moot and the majority of patients and referring physician are no longer willing to accept a "watch and wait" policy since the introduction of VATS. Transthoracic CT-guided needle aspiration biopsy may be a valid alternative to confirm malignancy in situations where metastatic lesions are suspected, e.g. in patients with a history of malignancy presenting a new lung nodule at follow-up. However. its diagnostic accuracy for 

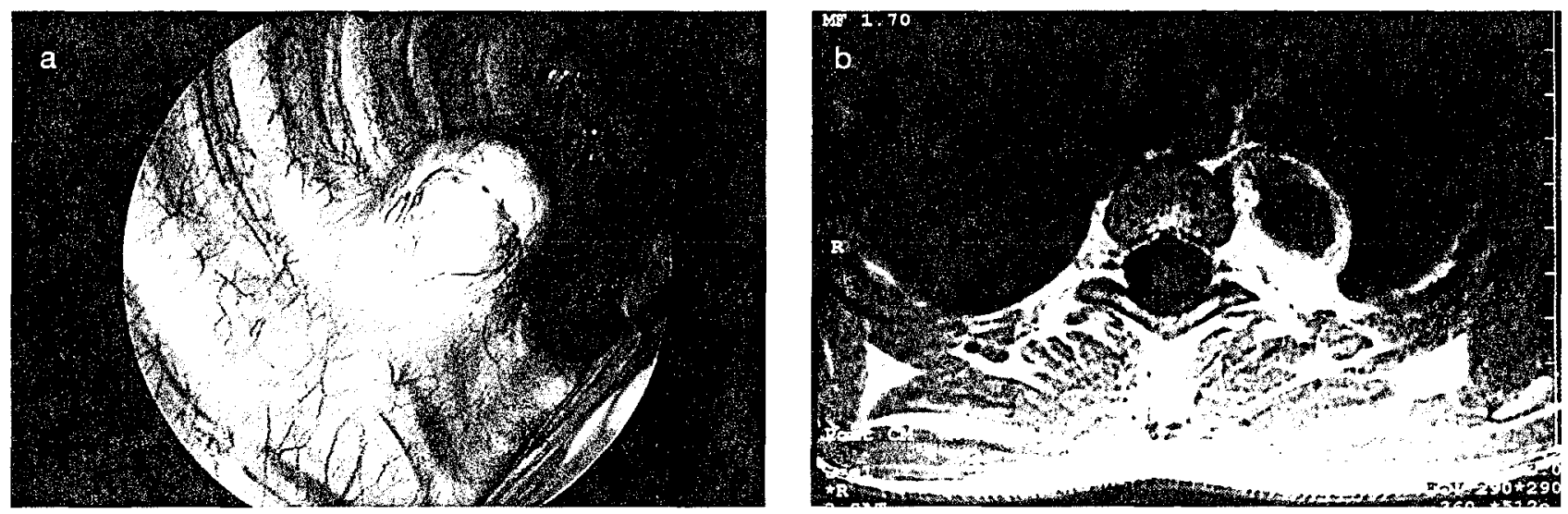

Fig. 3. Resection of a neurogenic tumor by use of VATS in an adult patient (a), after exchsion of extension within the spinal channel (dumbbell tumor) by use of a pre-operative $M R I(b)$.

benign lesions is as low as $50 \%$. Candidate pulmonary nodules for thoracoscopic resection are noncalcified lesions less than $3 \mathrm{~cm}$ in diameter located in the outer $3 \mathrm{rd}$ of the lung parenchyma or near a fissure with absence of endobronchial extension (17). Several techniques have been described to improve the identiftcation for the lesions during operation, including preoperative CT hook wire localization or intraoperative ultrasonic examination. However, total collapse of the lung and increasing experience with instrumental palpation of the parenchyma facilitates identification of most subpleural lesions. All excised nodules should be extracted by use of an Endobag device to prevent tumor implantation at the trocar sites.

Pneumothorax: Both, primary and secondary pneumothoraces are well recognized entities for a VATS approach. Blebs and bullae are probably better localized and identified by use of VATS (with its panoramic view of the entire chest cavity) than by a key-hole view through a small axillary thoracotomy. The lesions are resected by wedge resection using stapling devices followed by a pleurectomy of the apex or a mechanical abrasion of the parietal pleura by use of a sponge or a piece of surgicos. Most centers now perform an abrasion instead of a pleurectomy in order to avoid bleeding complications and injury to intercostal nerves. If no bleb or bulla can be visualized, resection of the apex of the lung is recommended in order to reduce late recurrence. There is increasing evidence in the literature that VATS seems to offer similar long-term results as conventional surgery in the surgical treatment of pneumothorax $(5,20,22,26)$.

Lung volume reduction surgery: VATS is an excellent tool to accomplish lung volume reduction surgery in selected patients with severe heterogeneous lung emphysema (27). This ap-

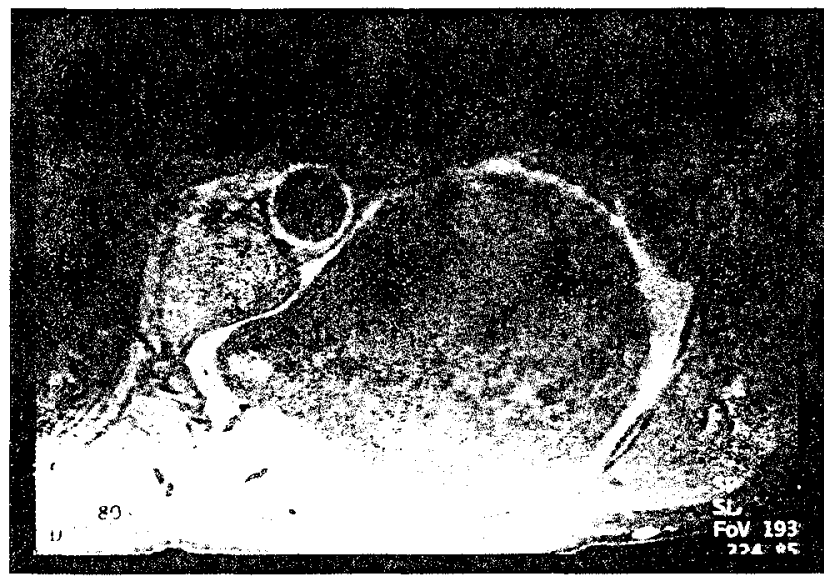

Fig. 4. Neurogenic tumors may be confounded with a thoracic meningocele (Figure) which should not be resected. proach is probably better tolerated than sternotomy in those patients with very limited reserves, especially in the early postoperative period, with better preservation of the chest wall integrity leading to better mobilization, coughing and clearance of secretion. We have performed unilateral VATS-LVRS in a consecutive series of 25 patients. with minimal morbidity and no requirement of reintubation, tracheotomy and prolonged ICU stay (9).

Lung cancer: Early stage non-small cell lung cancer is best dealt with lobectomy or pneumonectomy and mediastinal lymph node dissection. Non-anatomical resections bear a 3 to 5 fold risk of local recurrence as compared to lobectomy, even in stage I disease (11). Formal mediastinal lymph node dissection does increase the accuracy of staging and eliminates the risk to leave disease behind which. since unrecognized. will inevitably lead to local recurrence and significant local complications (18). Several studies have demonstrated that lymph node dissection is not associated with a higher morbidity than sampling and one prospective trial has documented an overall survival advantage over sampling in selected patients (15). Although anatomical resections may be performed by use of VATS, there is no evidence so far that mediastinal lymph node dissection is equally well performed than by conventional surgery. Many centers believe that the balance between completeness of resection (including avoidance of pleural or chest wall seeding) and postoperative morbidity is not in favor to VATS as compared to conventional surgery for the treatment of lung cancer $(7,12,16)$.

Pulmonary metastases: VATS is useful in the management of patients with pulmonary metastasis. When a needle biopsy cannot be performed or if the biopsy fails to yield a diagnosis. VATS can obtain sufficient tissue for analysis with a high degree of success. However. the role of VATS in potential therapeutic resections is uncertain and needs to be clarified further. One of the strongest predictor regarding long-term survival after pulmonary metastasectomy is complete resection at operation (23). However, it has been demonstrated that VATS resection of lung metastases performed in the intention to remove all disease, will leave behind gross disease in as much as $50 \%$ of the patients, as found at conventional surgery following the VATS procedure (21).

\section{Mediastinal diseases}

Biopsy of mediastinal masses: VATS is an excellent option to access lesions of unknown origin in the posterior and inferior mediastinum not accessible by mediastinoscopy or anterior mediastinotomy (8). Lesions within the aorto-pulmonary window may also be accessed by VATS. In addition, all mediastinal lymph nodes (N2) are theoretically accessible at VATS, subcarinal nodes being more easily accessed from the right side. However, lesions situated along the tracheobronchial tree are 

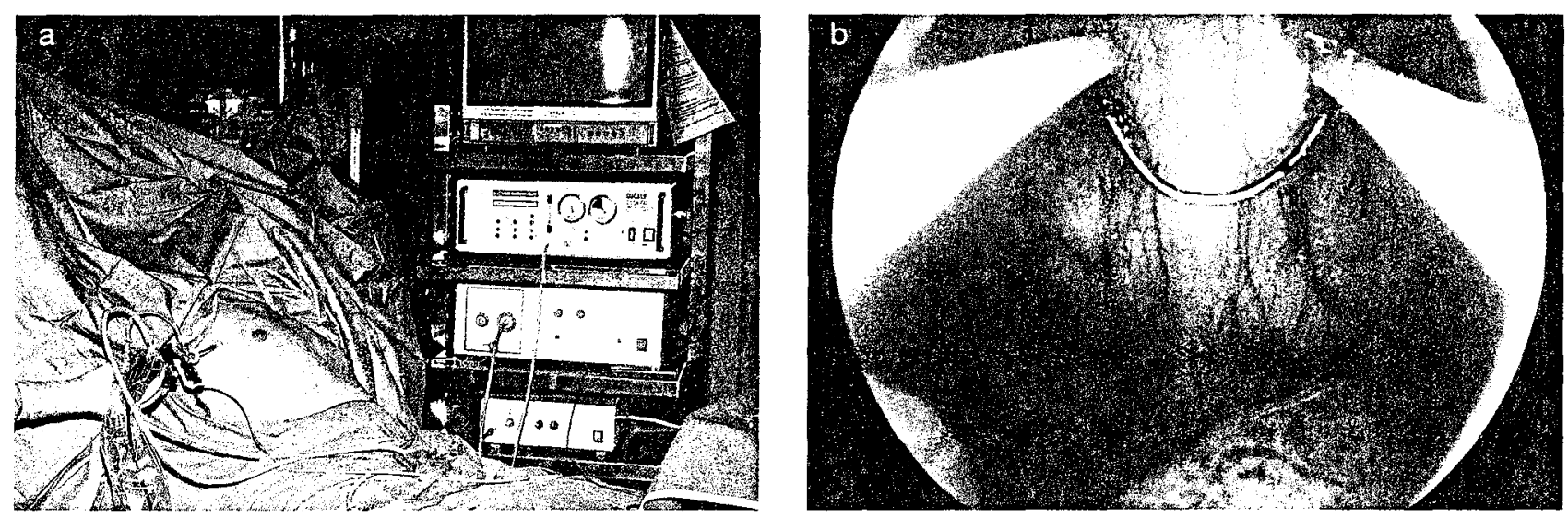

Fig. 5. Bilateral simultaneous symphatectomy by use of a urological cysto-resectoscope introduced through a single thoracoport in the axilla with the patient in the supine position (a). The sympathetic chain is then coagulated over the ribs $I I-V(b)$.

preferably accessed by transbronchial needle aspiration or mediastinoscopy. Mediastinoscopy remains the surgical procedure of choice for accessing levels 2, 4, 7 especially for staging of lung cancer since mediastinoscopy allows the simultaneous exploration of both sides without requiring double lumen intubation, and with lesser morbidity than thoracoscopy (8). Although masses in the anterior mediastinal compartment maly also be accessed by VATS we do not feel comfortable to use this technique for this purpose: $60 \%$ of these lesions are malignant and most frequently related to lymphoma, thymoma or germ cell tumors. Every effort should be made to keep the disease confined within the anterior compartment during biopsy in order to prevent contamination of the pleural cavity. Many centers prefer CT-guided tru-cut biopsy or anterior mediastinotomy for this purpose (8).

Thymectomy is indicated in the treatment of myasthenia gravis and thymoma. Both indications require a complete removal of the entire thymic gland (which has demonstrated great individual variation regarding its anatomical configuration) and a complete clearance of the entire mediastinal fat from phrenic nerve to phrenic nerve (4). This is required to remove ectopic thymic tissue which is found outside the thymic capsule in up to 70 to $80 \%$ of patients. We feel that this goat is best accomplished through a median sternotomy. There is some evidence in the literature that less extensive resection may result in inferior long-term results especially regarding remission rates after thymectomy for myasthenia gravis. To improve the cosmetical results in women we have performed a submammar incision followed by epifascial dissection and a longitudinal sternotomy, with excellent results in 25 patients. If a less invasive approach is desired, transcervical thymectomy is usually preferred over VATS since satisfactory results can be obtained with lesser morbidity than with VATS-thymectomy (6).

Resection of mediastinal cysts and neurogenic tumors: Mediastinal cysts may arise from malformations of the ventral and dorsal foregut, resulting in bronchogenic and enteric cysts, respectively. Excision is usually recommended to prevent complications such as infections or compression of adjacent structures, and malignant degeneration $(1,13)$. VATS is well-suited in this respect if resection is anticipated. Lymphangioma or cysts arising from the thoracic duct, however, are better approached by conventional thoracotomy or by a hemiclamshell incision in order to achieve complete excision. Neurogenic tumors are frequently situated in the paravertebral groove, arising from the sympathetic chain or the intercostal nerves. They are usually benign in adults and can be well excised by VATS provided that there is no extension into the spinal channel (dumbbell tumors) which must be excluded preoperatively by CT or MRI (Fig. 3). Large neurogenic tumors in patients with known Recklinghausen disease should be approached by conventional surgery since these tumors have usually undergone malignant degeneration. Neurogenic fumors in the pleural dome should only be approached by VATS if a preoperative MRI has excluded adjacency to the brachial plexus, otherwise these lesions must be dissected by an experienced plexus surgeon through a supraclavicular approach. Finally, neurogenic tumors may be confounded with a thoracic meningocele which should not be excised (Fig. 4).

Symphatectomy: Thoracic symphatectomy is indicated in impending finger gangrene due to arterial insufficiency not amenable to vascular reconstruction and helps to prevent or minimize tissue loss (25). However, it is not indicated in Raynaud's phenomenon due to the high recurrence rate observed after a short period of time in this situation. Hyperhydrosis palmaris and erythrophobia are other indications for symphatectomy which will result in surprisingly gratifying and long-lasting results (14). We and others use a cysto-resectoscope introduced through a single thoracoport in the axilla behind the pectoralis major muscle and coagulate the sympathetic chain over the ribs Il to $\mathrm{V}$ (Fig. 5). This procedure can be performed bilaterally during the same operation with the patient in the supine position. There were no complications observed in our 63 patients operated by this technique, with good results being observed in all patients. Therefore, we do not feel that excision of the sympathetic chain is necessary which requires a full lateral position and 3 thoracoports on each side.

\section{References}

(1) Bonavina L. Puvanello M. Baisi A. Castoro C. Ancona E. Perrachia A: Mediastinal cysts involving the oesophagus: diagnosis and results of surgical treatment. Eur J Surg 1996: 162: 703-707.

(2) Boutin C. Rey F. Viallat JR: Prevention of malignant seeding after invasive diagnostic procedures in patients with pleural mesothelioma. Chest 1995; 108:754-758. (3) Caccavale RJ, Arzouman DA: Video-assisted thoracic surgery for pleural disease. Chest Surg Clin N Am 1993: 2: 263-269.

(4) Drachman DB: Myasthenia gravis. N Engl J Med 1994; 330: 1797-1810.

(5) Dumont P. Diemont F. Massard G. Toumieux B. Whilm JM. Morand G: Does a thoracoscopic approach for surgical treatment of spontaneous pneumothorax represent progress? Eur J Cardiothorac Surg 1997; 11:27-31.

(6) Perguson MK: Transcervical thymectomy. Chesi Surg Clin N An 1996; 6: i05116

(7) Furter M, Rechsteiner R, Eigenmann V, Signer CH. Althaus U, Ris H-B: Thoracotomy vs video-assisted thoracoscopic surgery: Differences in postoperative pulmonary function, pain and chest wall complaints. Eur J Thorac Cardiovasc Surg 1997; 12: 82-87.

(8) Furrer M. Siriffeler H. Ris HB: Invasive Diagnostik bei mediastinalen Raumforderungen: Zur Differentialindikation zwischen cervikaler Mediastinoskopie, parasternaler Mediastinotomie und Video-Thoracoscopie. Chirurg 1995; 66: 12031209

(9) Geiser T, Gugger M, Schwizer B. Im Hof V. Ris HB: Unilateral lung volume re duction surgery in patients with emphysema Am J Resp Crit Care Med 1998: 157A: 334.

(10) Geissbuhler K, Fuhrer, Ris HB: Video-assisted pericardial fenestration for lo(10) Geissbihter K, Fuhrer, Ris HB: Video-assisted pericardial fene
clilited pericardial effusions. Eur J Cardiohorac Surg (in press).

(ii) Ginsberg RJ, Rubinstein LV, for the Lung Cancer Study Group: Randomized trial of lobectomy $v s$ limited resection for resection for TINO non-small cell lung cancer. Ann Thorac Surg 1995; 60: 615-623. 
(12) Giudicelli R. Thomas P. Lonjon T. Ragni J. Morati N. Otomani R. Fuentes PA. Shennib H. Noirclere M: Video-ilssisted minithoracotomy versus muscle sparing thoracotomy for performing lobectomy. Ann Thorac Surg 1994: 58: 712-718.

(13) Hazelrigg SR. Mack MJ, Landreneau RJ: Video-assisted thoracic surgery for mediastinal disease. Chest Surg Clin N Am 1993:2: 283-297.

(14) Hsu CP. Chen CY. Lin CT. Wang JH. Chen CL. Wang PY: Video-assisted thoracoscopic T2 symphalectomy for hyperhydrosis palmaris. J Am Coll Surg 1994: 179: $59-64$

(I5) Izhicki JR, Passlick B, Pantel K. Pichlmeier U, Hosch SB, Karg O. Thetter O: Effectiveness of radical systematic mediastinal lymphadenectomy in patients with resectable non-small cell lung cancer. Ann Surg 1998: 227: 138-144

(16) Kirby TJ Mack MJ, Lindrenciau RJ, Rice TW: Lobectomy: videonassisted thoracic surgery versus muscle-sparing thoracotomy: a randomized trial. J Thorac Cardiovase Surg 1995; 109: 997-1002.

(17) Landrencau RJ. Mack MJ. Hatzelrigg SR. Dowling RD. Keenan RJ. Ferson PF: Thoracoscopic management of benign pulmonary lesions. Chest Surg Clin N Am $1993: 3: 249-262$

(18) Martini N: Mediastinal lymph node dissection for lung cancer: the memorial experience. Chest Surg Clin N Am 1995: 5: 198-203.

(19) Meyer DM. Jessen MA. Wait MA, Estrera AS: Early cvacuation of trilumatic hemothoraces using thoracoscopy - a prospective randomized trial. Ann Thoric Surg (in press).

(20) Mouroux J. Elkim D. Paldovani B. Myx A. Perrin C. Rotomondo C. Chavaillon JM, Blaive B. Richelme H: Video-atsisted thoracoscopic treatment of spontane- ous pneumothorax: technique and results from one hundred cases $\mathrm{J}$ Thoric Cardiovase Surg 1996: 112:385-391.

(21) McCornack P. PM. Bains MS, Begg CB. Burt ME, Downey RJ, Panicek DM. Rusch VW, Zakowski M, Ginsberg RJ: Role of video-assisted thoracic surgery in the treatment of pulmonary metastases: results of a prospective trial. Ann Thorac Surg 1996; 62: $213-217$

(22) Naunheim KS. Mack MJ. Hazelrigg SR. Fergusion MK. Ferson PF. Bolcy TM. Landireneau RJ: Safety and efficacy of video-assisted thoracic surgical techntuues for the treatment of spontaneous pneumothorax. J Thorac Cardiovasc Surg 1995: 109: $1198-1203$

(23) Pastorino U, McCormack PM, Ginsberg RJ: A new staging proposal for pulmonary metastases. Chese Surg Clin N Am 1998: 8: 197-202.

(24) Striffeler H, Gugger M. Im Hof V. Cerny A, Furrer M, Ris H-B: Videoassisted thoracoscopic surgery for fibrinopurulent empyema: a consecutive series of $67 \mathrm{pa}$ tients. Ann Thorac Surg 1998; 65:319-323.

(24) Urschel HC: Dorsal symphatectomy and management of thoracic outlet syn drome with VATS. Ann Thorac Surg 1993; 56: 717-720.

(25) Willer DA. Forty J, Morrit GN: Videoassissted thoracoscopic surgery versus thoracotumy for spontancous pneumothorax. Ann Thorac Surg 1994: 58: 372-377. (26) Weder W. Thurnheer R. Stammberger U, Bürge M, Russi EW. Bloch KE. Ra diologic emphysema morphology is associated with outcome after surgical lung volume reduction. Ann Thorace Surg 1997; 64: 313-320.

(27) Yim AP, Chan AT, Lee TW, Wan IY. Ho JK: Thoracoscopic talc insufflation versus tale slurry fier symptomatic malignant pleural effusion. Ann Thorac Sura $1996: 62 \cdot 1655-1658$

\section{Kongreßankündigung / Congress Announcement}

\section{Internationales Symposium für Kinderchirurgie}

Oret:

Obergurgl/ Tirol

Termin:

31. 1. -2.2 .2000$

Therioner:

Infektionen und Sepsis in der Kinderchirurgie freie Themen (Aktuelles, Kontroversielles, Forschung)

Anpritdung: Armeldung per E-mail: ernsthorcher@akh-wien.ac.at oder: http://www.akh-wien.ac.at/pediatric-surgery/

Abstracts: Abstracts-Formular im Internet: http://www.blackwell.de/aca.htm Alle angenommenen Abstracts werden in der ACTA CHIRURGICA AUSTRIACA - European Surgery veröffentlicht.

Informationen: Klinische Abteilung für Kinderchirurgie der Universität Wien (Leiter: Prof. Dr. E. Horcher) Währinger Gürtel 18-20, A-1090 Wien. Tel. $++43 / 1 / 40400-6836$, Fax: $++43 / 1 / 40400-6838$. 